\title{
Epidemiology of Prehypertension and Associated Risk Factors in Urban Adults From 33 Communities in China - The CHPSNE Study -
}

\author{
Xiu-Jun Meng, MD; Guang-Hui Dong, PhD; Da Wang, MD; Miao-Miao Liu, MD; Yu-Qin Liu, MD; \\ Yang Zhao, MD; Wei-Wei Deng, PhD; Shen Tian, PhD; Xin Meng, PhD; Hai-Yan Zhang, PhD
}

\begin{abstract}
Background: The Seventh Report of The Joint National Committee has recently introduced the prehypertension category of blood pressure (BP) status that needs monitoring and intervention. Little is known about the epidemiology of prehypertension in urban China, so this study aimed at estimating the prevalence of prehypertension and identifying risk factors in urban Chinese adults.
\end{abstract}

\begin{abstract}
Methods and Results: Using a multistage cluster and random sampling method, a representative sample of 25,196 urban adults aged 18-74 years in northeast of China was selected from 2009 to 2010 . The survey of BP and associated risk factors was carried out in 33 communities. Multiple logistic regression methods were used to identify risk factors for prehypertension. Overall, $40.5 \%$ of urban Chinese adults had prehypertension, with a prevalence of $47.7 \%$ and $33.6 \%$ in men and women, respectively. Multivariate logistic regression analysis revealed the risk factors of being overweight (adjusted odds ratio $[\mathrm{aOR}]=1.38,95 \%$ confidence interval $[\mathrm{Cl}]$ : 1.26-1.52), obesity (aOR=3.94, $95 \% \mathrm{Cl}: 2.99-5.20)$, central obesity $(\mathrm{aOR}=2.13,95 \% \mathrm{Cl}: 1.96-2.32)$. Being female, and having a higher education level, higher family income and diet control were protective factors.
\end{abstract}

Conclusions: Prehypertension is common among urban residents in China, and is associated with many risk factors. Comprehensive lifestyle modifications need to be taken to decrease the incidence of prehypertension and to prevent prehypertension progressing to hypertension and cardiovascular disease. (Circ J 2012; 76: 900-906)

Key Words: China; Prehypertension; Risk factors; Urban adults

D uring the past decade, China has experienced rapid economic development, followed by changes in lifestyle and diet, and cardiovascular disease (CVD) has become the leading cause of death in China. ${ }^{1}$ Hypertension (blood pressure (BP) $>140 / 90 \mathrm{mmHg}$ ) has been identified as the major risk factor for CVD and other vascular diseases. ${ }^{2-5}$ However, some authors have reported that CVD risk increases steadily with even slightly elevated BP $(>115 / 70 \mathrm{mmHg}){ }^{6}$ Thus, in 2003, the Seventh Joint National Committee on the Prevention, Detection, Evaluation, and Treatment of High Blood Pressure (JNC7) introduced a new category of BP status termed "prehypertension" and defined as systolic BP (SBP) of $120-139 \mathrm{mmHg}$ or diastolic BP (DBP) of $80-89 \mathrm{mmHg}$ in adults aged 18 years or older, with the recommendation that healthcare providers monitor these patients closely. ${ }^{7}$ In recent years, studies have assessed the prevalence and associated risk profiles of prehypertension, and the increased CVD risk in prehypertensive subjects has been confirmed in some reports. ${ }^{6,8-12}$ However, few studies have assessed the epidemiology of prehypertension among Chinese, especially among urban adults. In addition, racial and ethnic differences are known to influence the prevalence and risks of prehypertension. ${ }^{13,14}$ In this study, we assessed the prevalence of prehypertension and associated risk profiles in an urban Chinese adult population.

\section{Sample Design}

The Control Hypertension and Other Risk Factors to Prevent

Received October 10, 2011; revised manuscript received November 21, 2011; accepted December 1, 2011; released online February 1, 2012 Time for primary review: 30 days

Department of Geriatrics, First Affiliated Hospital of China Medical University, Shenyang (W.-W.D., X.M., H.-Y.Z.); Department of Biostatistics and Epidemiology, School of Public Health, China Medical University, Shenyang (G.-H.D., D.W., M.-M.L., Y.-Q.L., Y.Z.); and Division of Neurology, Fourth Affiliated Hospital of China Medical University, Shenyang (X.-J.M., S.T.), PR China

Mailing address: Guang-Hui Dong, PhD, School of Public Health, China Medical University, 92 North $2^{\text {nd }}$ Road, Heping Districts, Shenyang 110001, PR China. E-mail: ghdong@mail.cmu.edu.cn

ISSN-1346-9843 doi:10.1253/circj.CJ-11-1118

All rights are reserved to the Japanese Circulation Society. For permissions, please e-mail: cj@j-circ.or.jp 
Stroke with Nutrition Education in Urban Area of Northeast China (CHPSNE) Study was a cross-sectional study of hypertension and stoke disease risk factors among urban residents of northeast China aged 18-74 years, and a detailed description of the study's methods have been given elsewhere. ${ }^{15} \mathrm{~A}$ representative sample of urban Chinese residents was sampled during $2009-2010$ by a 3 -stage stratified sampling method. A total of 28,830 people were selected and invited to participate in the survey, which a total of 25,196 (12,413 men, 12,783 women) completed. The overall response rate was $87.4 \%$ and was similar between men and women.

\section{Data Collection}

Data were collected in examination centers at local health stations or community clinics in the participants' residential areas. During the visits, trained research staff administered a standard questionnaire in Chinese to obtain information on demographic characteristics, including age, sex, education, and occupation. The interview included questions related to the diagnosis and treatment of hypertension.

\section{BP Measurement and Classification}

Three BP measurements were obtained for each participant by trained and certified observers according to a common protocol adapted from procedures recommended by the American Heart Association. ${ }^{16} \mathrm{BP}$ was measured three times with the participant seated after a 5-min rest, and the time interval between each of the 3 measurements of BP was $2 \mathrm{~min}$. In addition, participants were advised to avoid alcohol, cigarette smoking, coffee/tea, and exercise for at least $30 \mathrm{~min}$ before their BP measurements. A standardized mercuric-column sphygmomanometer was used, and 1 of 4 cuff sizes (pediatric, regular adult, large, or thigh) was chosen based on the circumference of the participant's arm.

The classification of normotensive, prehypertensive and hypertensive was based on the classification of BP from JNC7. ${ }^{7}$ Normal BP was defined as not being on antihypertensive medication and having SBP $<120 \mathrm{mmHg}$ and $\mathrm{DBP}<80 \mathrm{mmHg}$. Prehypertension was defined as not being on antihypertensive medication and having SBP of $120-139 \mathrm{mmHg}$ or DBP of $80-89 \mathrm{mmHg}$.

\section{Height and Weight Measurements}

Body weight, body height, waist circumference (WC), and hip circumference were measured using a standardized protocol. Height was measured, to the nearest $0.5 \mathrm{~cm}$, without shoes, back square against the wall tape, eyes looking straight ahead with a right-angle triangle resting on the scalp and against the wall. Weight was measured with a lever balance to the nearest $100 \mathrm{~g}$, without shoes, in light undergarments. WC was defined as the midpoint between the lower rib and upper margin of the iliac crest, measured by a nurse using a tape with an insertion buckle at 1 end. WC was measured at $0.5 \mathrm{~cm}$ above the navel under minimal respiration and hip circumference at the level of maximum extension of the buttocks. Body mass index (BMI) was calculated as weight divided by height squared $\left(\mathrm{kg} / \mathrm{m}^{2}\right)$. According to the definition proposed by the World Health Organization (WHO), subjects with BMI $\geq 25 \mathrm{~kg} / \mathrm{m}^{2}$ and $<30 \mathrm{~kg} / \mathrm{m}^{2}$ were classified as overweight and those with BMI $\geq 30 \mathrm{~kg} / \mathrm{m}^{2}$ were classified as obese. Central obesity is defined as WC $\geq 85 \mathrm{~cm}$ in men and $\geq 80 \mathrm{~cm}$ in women. ${ }^{17}$

\section{Statistical Analysis}

Continuous variables are given as the mean \pm SD and categorical variables as the percentage in each subgroup. Compari-

\begin{tabular}{|c|c|c|c|}
\hline Age (years) & $n$ & PHT (\%) & HT (\%) \\
\hline \multicolumn{4}{|l|}{ Men } \\
\hline $18-34$ & 5,028 & 55.1 & 19.8 \\
\hline $35-44$ & 2,560 & 48.6 & 30.8 \\
\hline $45-54$ & 2,469 & 43.9 & 41.2 \\
\hline $55-64$ & 1,426 & 36.8 & 52.7 \\
\hline $65-74$ & 930 & 31.9 & 56.5 \\
\hline Total & 12,413 & 47.7 & 32.9 \\
\hline \multicolumn{4}{|l|}{ Women } \\
\hline $18-34$ & 4,792 & 31.7 & 4.7 \\
\hline $35-44$ & 2,693 & 38.8 & 16.9 \\
\hline $45-54$ & 2,689 & 36.7 & 36.4 \\
\hline $55-64$ & 1,670 & 29.3 & 55.9 \\
\hline $65-74$ & 939 & 26.6 & 60.4 \\
\hline Total & 12,783 & 33.6 & 24.7 \\
\hline \multicolumn{4}{|l|}{ All } \\
\hline $18-34$ & 9,820 & 43.7 & 12.4 \\
\hline $35-44$ & 5,253 & 43.6 & 23.7 \\
\hline $45-54$ & 5,158 & 40.2 & 38.7 \\
\hline $55-64$ & 3,096 & 32.8 & 54.5 \\
\hline $65-74$ & 1,869 & 29.3 & 58.4 \\
\hline Total & 25,196 & 40.5 & 28.7 \\
\hline
\end{tabular}

PHT, prehypertension; HT, hypertension.

sons of continuous variables between groups were performed by t-test. The associations between categorical variables were tested using contingency tables and the $\chi^{2}$ test. We calculated adjusted odds ratios (ORs) with 95\% confidence intervals $(95 \% \mathrm{CI})$ for prehypertension and hypertension using univariate and multivariate logistic regression models. All data analyses were conducted using SAS software (Version 9.1; SAS Institute Inc, Cary, NC, USA). All statistical tests were 2tailed, and $\mathrm{P}<0.05$ was considered statistically significant. In the 5 age groups, the percentage of persons with prehypertension was greater in men than in women.

\section{Results}

The mean age of the subjects in this analysis was 41.7 years (SD 14.4 years). Of them, 7,746 individuals had normal BP, 10,213 were prehypertensive, and 7,237 were hypertensive. Approximately $40.5 \%$ of these urban Chinese adults had prehypertension. The overall prevalence rate of prehypertension was higher among men (47.7\%) than women (33.6\%). Among the men, there was a persistent, increasing trend of prehypertension prevalence associated with an increase in age, but among the women, the prevalence of prehypertension increased up to the age of 35-44 years and then decreased (Table 1).

Table 2 lists the baseline characteristics of the prehypertensive and normotensive subjects. Individuals with prehypertension $(40.0 \pm 13.7)$ or hypertension $(50.1 \pm 13.7)$ were significantly older than those with normal BP (36.0 \pm 12.3$) ; 56.4 \%$ of the hypertensive, $58.0 \%$ of the prehypertensive and $31.1 \%$ of the normotensive individuals were males $(\mathrm{P}<0.001)$. Of these, $0.8 \%$ of the normotensive, $4.1 \%$ of the prehypertensive, and $11.4 \%$ of the hypertensive subjects were obese (BMI $\geq 30$ ), and $16.1 \%, 29.3 \%$ and $42.5 \%$, respectively, were overweight $(25 \leq \mathrm{BMI}<30)$. The central obesity percent rate was signifi- 


\begin{tabular}{|c|c|c|c|c|}
\hline & $\begin{array}{c}\text { NT } \\
(n=7,746)\end{array}$ & $\begin{array}{c}\text { PHT } \\
(n=10,213)\end{array}$ & $\begin{array}{c}\mathrm{HT} \\
(\mathrm{n}=\mathbf{7 , 2 3 7 )}\end{array}$ & $P$ value \\
\hline Age (years) (mean $\pm S D)$ & $36.0 \pm 12.3$ & $40.0 \pm 13.7$ & $50.1 \pm 13.7$ & $<0.001$ \\
\hline Male, \% & $2,412(31.1)$ & $5,922(58.0)$ & $4,079(56.4)$ & $<0.001$ \\
\hline \multicolumn{5}{|l|}{ Ethnic group, \% } \\
\hline Han nationality & 7,146 (92.3) & $9,343(91.5)$ & $6,680(92.3)$ & 0.074 \\
\hline Other & $600(7.8)$ & $870(8.5)$ & $557(7.7)$ & \\
\hline \multicolumn{5}{|l|}{ Educational level, \% } \\
\hline No school & $183(2.4)$ & 354 (3.5) & $446(6.2)$ & $<0.001$ \\
\hline Primary school & $706(9.1)$ & $1,289(12.6)$ & $1,230(17.0)$ & \\
\hline Junior high school & $4,310(55.6)$ & $6,103(59.8)$ & $4,323(59.7)$ & \\
\hline$\geq$ Senior high school & 2,547 (32.9) & $2,467(24.2)$ & $1,238(17.1)$ & \\
\hline \multicolumn{5}{|l|}{ Occupation, \% } \\
\hline Blue-collar worker & $4,046(52.2)$ & $4,741(46.4)$ & $3,100(42.8)$ & $<0.001$ \\
\hline White-collar worker & $1,313(17.0)$ & $1,589(15.6)$ & $1,109(15.3)$ & \\
\hline Organization cadre & $422(5.5)$ & $787(7.7)$ & $685(9.5)$ & \\
\hline Other & $1,965(25.4)$ & $3,096(30.3)$ & $2,343(32.4)$ & \\
\hline \multicolumn{5}{|l|}{ Family income/year, \% } \\
\hline$<10,000 \mathrm{RMB}$ & $525(6.8)$ & $1,003(9.8)$ & $956(13.2)$ & $<0.001$ \\
\hline $10,000-30,000 \mathrm{RMB}$ & $897(11.6)$ & 1,393 (13.6) & $996(13.8)$ & \\
\hline $30,000-50,000 \mathrm{RMB}$ & $3,989(51.5)$ & $5,381(52.7)$ & $3,638(50.3)$ & \\
\hline$>50,000 \mathrm{RMB}$ & $2,339(30.2)$ & $2,436(23.9)$ & $1,647(22.8)$ & \\
\hline \multicolumn{5}{|l|}{ BMI group $\left(\mathrm{kg} / \mathrm{m}^{2}\right), \%$} \\
\hline$<25$ & $6,436(83.1)$ & $6,794(66.5)$ & $3,337(46.1)$ & $<0.001$ \\
\hline$\geq 25-<30$ & $1,246(16.1)$ & $2,996(29.3)$ & $3,076(42.5)$ & \\
\hline$\geq 30$ & $64(0.8)$ & $423(4.1)$ & $824(11.4)$ & \\
\hline \multicolumn{5}{|l|}{ WC $(\mathrm{cm}), \%$} \\
\hline Men $<85$, women $<80$ & $5,934(76.6)$ & $5,391(52.8)$ & $2,354(32.5)$ & $<0.001$ \\
\hline Men $\geq 85$, women $\geq 80$ & $1,812(23.4)$ & $4,822(47.2)$ & $4,883(67.5)$ & \\
\hline \multicolumn{5}{|l|}{ Diabetes, $\%$} \\
\hline No & $7,590(98.0)$ & $9,977(97.7)$ & $6,765(93.5)$ & $<0.001$ \\
\hline Yes & $156(2.0)$ & $236(2.3)$ & $472(6.5)$ & \\
\hline \multicolumn{5}{|l|}{ Family history of $\mathrm{HT}, \%$} \\
\hline No & $5,574(72.0)$ & $7,323(71.7)$ & $3,986(55.1)$ & $<0.001$ \\
\hline Yes & $2,172(28.0)$ & $2,890(28.3)$ & $3,251(44.9)$ & \\
\hline \multicolumn{5}{|l|}{ Cigarette smoking, \% } \\
\hline Never & $6,009(77.6)$ & $6,511(63.8)$ & $4,660(64.4)$ & $<0.001$ \\
\hline Current & $1,578(20.4)$ & $3,343(32.7)$ & $2,173(30.0)$ & \\
\hline Former & $159(2.1)$ & $359(3.5)$ & $404(5.6)$ & \\
\hline \multicolumn{5}{|l|}{ Alcohol consumption, $\%$} \\
\hline$<2$ drinks/day & 6,695 (86.4) & 7,826 (76.6) & $5,561(76.8)$ & $<0.001$ \\
\hline$\geq 2$ drinks/day & $1,051(13.6)$ & $2,387(23.4)$ & $1,676(23.2)$ & \\
\hline \multicolumn{5}{|l|}{ Eating fried food, $\%$} \\
\hline Never & $6,045(78.0)$ & $7,793(76.3)$ & $5,982(82.7)$ & $<0.001$ \\
\hline Yes & $1,701(22.0)$ & $2,420(23.7)$ & $1,255(17.3)$ & \\
\hline \multicolumn{5}{|c|}{ Controlled diet (low calorie and fat), \% } \\
\hline No & $5,502(71.0)$ & $7,134(69.9)$ & $4,729(65.3)$ & $<0.001$ \\
\hline Yes & $2,244(29.0)$ & $3,079(30.2)$ & $2,508(34.7)$ & \\
\hline
\end{tabular}

Data are $\mathrm{n}(\%)$. Comparisons among subjects defined as NT, PHT and HT were performed with ANOVA or $X^{2}$ test. NT, normotension; RMB, renminbi; BMI, body mass index; WC, waist circumference. Other abbrevistions see in Table 1.

cantly higher in hypertensive $(67.5 \%)$ and prehypertensive subjects $(47.2 \%)$ than in those who were normotensive $(23.4 \%)$. Education status, occupation, family income, smoking, drinking, and lifestyle were significantly different between groups $(\mathrm{P}<0.001)$.

Univariate logistic regression showed that age, sex, ethnic- ity, education status, occupation, family income, BMI, WC, smoking, drinking, and eating fried food were significantly associated with prehypertension status for the whole sample (Table 3). After multiple logistic regression analysis, age, male sex, ethnicity, occupation, BMI and WC were the main risk factors. Compared with people aged 18-34 years, people 


\begin{tabular}{|c|c|c|c|c|}
\hline & \multicolumn{2}{|c|}{ Univariate analysis } & \multicolumn{2}{|c|}{ Multivariate analysis* } \\
\hline & OR $(95 \% \mathrm{Cl})$ & $P$ value & OR $(95 \% \mathrm{Cl})$ & $P$ value \\
\hline Age group (years): 18-34 & 1.00 (reference) & & 1.00 (reference) & \\
\hline $35-44$ & $1.34(1.24-1.44)$ & $<0.001$ & $1.20(1.10-1.30)$ & $<0.001$ \\
\hline $45-54$ & $1.91(1.75-2.07)$ & $<0.001$ & $1.51(1.37-1.67)$ & $<0.001$ \\
\hline $55-64$ & $2.57(2.27-2.91)$ & $<0.001$ & $1.88(1.63-2.17)$ & $<0.001$ \\
\hline $65-74$ & $2.39(2.03-2.80)$ & $<0.001$ & $1.63(1.35-1.96)$ & $<0.001$ \\
\hline Male (ref: female) & $3.05(2.87-3.25)$ & $<0.001$ & $3.61(3.31-3.93)$ & $<0.001$ \\
\hline \multicolumn{5}{|l|}{ Ethnic group } \\
\hline Han nationality & 1.00 (reference) & & 1.00 (reference) & \\
\hline Other & $1.11(1.00-1.24)$ & 0.062 & $1.18(1.05-1.33)$ & 0.005 \\
\hline Educational level (ref: no school) & 1.00 (reference) & & 1.00 (reference) & \\
\hline Primary school & $0.94(0.77-1.15)$ & 0.573 & $0.82(0.66-1.02)$ & 0.088 \\
\hline Junior high school & $0.73(0.61-0.88)$ & $<0.001$ & $0.72(0.58-0.88)$ & 0.003 \\
\hline$\geq$ Senior high school & $0.50(0.42-0.60)$ & $<0.001$ & $0.51(0.41-0.64)$ & $<0.001$ \\
\hline \multicolumn{5}{|l|}{ Occupation } \\
\hline Blue-collar worker & 1.00 (reference) & & 1.00 (reference) & \\
\hline White-collar worker & $1.04(0.95-1.12)$ & 0.453 & $1.10(1.00-1.22)$ & 0.026 \\
\hline Organization cadre & $1.59(1.40-1.80)$ & $<0.001$ & $1.58(1.36-1.82)$ & $<0.001$ \\
\hline Other & $1.35(1.25-1.44)$ & $<0.001$ & $1.12(1.03-1.21)$ & 0.008 \\
\hline \multicolumn{5}{|l|}{ Family income/year } \\
\hline$<10,000 \mathrm{RMB}$ & 1.00 (reference) & & 1.00 (reference) & \\
\hline $10,000-30,000 \mathrm{RMB}$ & $0.81(0.71-0.93)$ & 0.003 & $1.09(0.94-1.26)$ & 0.229 \\
\hline $30,000-50,000 \mathrm{RMB}$ & $0.71(0.63-0.79)$ & $<0.001$ & $0.99(0.87-1.12)$ & 0.918 \\
\hline$>50,000 \mathrm{RMB}$ & $0.55(0.48-0.62)$ & $<0.001$ & $0.92(0.80-1.06)$ & 0.340 \\
\hline BMI group $\left(\mathrm{kg} / \mathrm{m}^{2}\right)$ (ref: <25) & 1.00 (reference) & & 1.00 (reference) & \\
\hline$\geq 25-<30$ & $2.28(2.12-2.45)$ & $<0.001$ & $1.38(1.26-1.52)$ & $<0.001$ \\
\hline$\geq 30$ & $6.26(4.80-8.16)$ & $<0.001$ & $3.94(2.99-5.20)$ & $<0.001$ \\
\hline \multicolumn{5}{|l|}{ WC $(\mathrm{cm})$} \\
\hline Men $<85$, women $<80$ & 1.00 (reference) & & 1.00 (reference) & \\
\hline Men $\geq 85$, women $\geq 80$ & $2.93(2.74-3.13)$ & $<0.001$ & $2.13(1.96-2.32)$ & $<0.001$ \\
\hline Diabetes (ref: No) & 1.00 (reference) & & 1.00 (reference) & \\
\hline Yes & $1.15(0.94-1.41)$ & 0.178 & $0.84(0.63-1.05)$ & 0.097 \\
\hline Family history of HT (ref: No) & 1.00 (reference) & & 1.00 (reference) & \\
\hline Yes & $1.01(0.95-1.08)$ & 0.705 & $1.20(1.12-1.30)$ & $<0.001$ \\
\hline \multicolumn{5}{|l|}{ Cigarette smoking } \\
\hline Never & 1.00 (reference) & & 1.00 (reference) & \\
\hline Current & $1.96(1.82-2.10)$ & $<0.001$ & $0.82(0.74-0.90)$ & $<0.001$ \\
\hline Former & $2.08(1.72-2.52)$ & $<0.001$ & $0.85(0.69-1.04)$ & 0.123 \\
\hline \multicolumn{5}{|l|}{ Alcohol consumption } \\
\hline$<2$ drinks/day & 1.00 (reference) & & 1.00 (reference) & \\
\hline$\geq 2$ drinks/day & $1.94(1.79-2.10)$ & $<0.001$ & $1.05(0.95-1.16)$ & 0.428 \\
\hline \multicolumn{5}{|l|}{ Eating fried food } \\
\hline Never & 1.00 (reference) & & 1.00 (reference) & \\
\hline Yes & $1.10(1.03-1.18)$ & 0.006 & $1.01(0.93-1.10)$ & 0.793 \\
\hline \multicolumn{5}{|l|}{ Controlled diet (low calorie and fat) } \\
\hline No & 1.10 (reference) & & 1.00 (reference) & \\
\hline Yes & $1.06(0.99-1.13)$ & 0.087 & $0.87(0.81-0.94)$ & $<0.001$ \\
\hline
\end{tabular}

*Adjusted for sex, age, ethnicity, education, occupation, family income, BMI, WC, diabetes, family history of HT, smoking status, drinking status, eating fried food, and diet control.

$\mathrm{OR}$, odds ratio; Cl, confidence interval. Other abbrevistions see in Tables 1,2.

aged 35-44, 45-54, 55-64 and $\geq 65$ years had more risks of getting prehypertension (adjusted odds ratio $(\mathrm{aOR})=1.20$, $1.51,1.88$, and 1.63 , respectively). Males were at higher risk of developing prehypertension as compared with females (aOR=3.61, 95\%CI: 3.31-3.93). Compared with blue-collar workers, prehypertension was higher in white-collar workers $(\mathrm{aOR}=1.10,95 \% \mathrm{CI}: 1.00-1.22)$ and organization cadres $(\mathrm{aOR}=1.58,95 \% \mathrm{CI}: 1.36-1.82)$. People who were overweight or obese are more likely to get prehypertension compared with people of normal weight $(25 \leq \mathrm{BMI}<30, \mathrm{aOR}=1.38$; $\mathrm{BMI} \geq 30$, 
$\mathrm{aOR}=3.94)$. Male and female participants with the same characteristics, apart from WC $\geq 85$ (male) or $\geq 80$ (female), had a higher risk of becoming prehypertensive $(\mathrm{aOR}=2.13,95 \% \mathrm{CI}$ : 1.96-2.32) than males with WC $<85$ and for females $<80$. In contrast, there was an inverse relationship between education level and the risk of prehypertension. Compared with those in the lowest education attainment group (no school), the risk of prehypertension decreased by $28 \%$ with education level of junior high school (aOR=0.72, 95\%CI: 0.58-0.88) and 49\% with senior high school $(\mathrm{aOR}=0.51,95 \% \mathrm{CI}$ : 0.41-0.64). Similarly, the occurrence of prehypertension was also negatively related to family income, though the relationship was not significant. In addition, controlled diet with low calorie and fat was significantly associated with a lower prevalence of prehypertension $(\mathrm{aOR}=0.87,95 \% \mathrm{CI}$ : $0.81-0.94)$.

To our surprise, the prevalence of prehypertension was higher in current smokers (47.1\%) and former smokers (38.9\%) than in never smokers $(37.9 \%)$. However, when adjusted for all other factors, including age, the current and former smokers appeared to have a lower risk of developing hypertension, especially current smokers $(\mathrm{aOR}=0.82,95 \% \mathrm{CI}$ : $0.74-0.90)$. A similar pattern was also observed in drinking status: univariate analysis showed that subjects consuming $\geq 2$ drinks per day appeared to have a higher risk for developing prehypertension than those consuming $<2$ drinks per day $(\mathrm{aOR}=1.94,95 \% \mathrm{CI}$ : 1.79-2.10); however, the adjusted OR for the prevalence of prehypertension decreased to nearly 1.0 and was not significant (95\%CI: 0.95-1.16).

\section{Discussion}

Using the JNC-7 Report's criteria for BP classification, our findings showed that the overall prevalence of prehypertension in urban Chinese was approximately $40.5 \%$, which exceeds that of many developing countries ${ }^{9,18,19}$ and is even higher than that in developed countries and regions. ${ }^{14,20}$ The overall prevalence of prehypertension in 15-74-year-old Jamaicans was estimated to be $30 \%$ in $2001 .^{9}$ The results from the Trabzon Hypertension Study showed that the prevalence of prehypertension in Turkish adults was only $14.5 \%$ (12.6\% in women and $16.8 \%$ in men). ${ }^{18} \mathrm{~A}$ recent study conducted in 5 Indian cities showed that the prevalence of prehypertension in Indian adults was only $28.7 \%$ (27.2\% in women, and $30.0 \%$ in men). ${ }^{19}$ Other published studies in developed countries of Asia reported that the prevalence of prehypertension was $31.6 \%$ in Korea, ${ }^{20} 32 \%$ in Japan, ${ }^{21}$ and $35.8 \%$ in Taiwan, ${ }^{22}$ which are all lower values than the prehypertension percentage in the present study. Even compared with results from Europe and America, the prevalence of prehypertension in urban Chinese adults in northeast China is still higher. Results from the SUNSET study conducted in Europe showed that the overall prevalence of prehypertension was $32.8 \% .{ }^{14}$ In the United States, the prevalence of prehypertension in an adult population 18 years and older was $31 \%$ (41\% in men and $23 \%$ in women). ${ }^{23}$ Also, compared with other surveys in China, the prevalence of prehypertension in the present study is still higher. The results of the International Collaborative Study of Cardiovascular Disease in ASIA (InterASIA), conducted in 2000-2001, showed that the overall prevalence of prehypertension in Chinese aged 35-74 years from urban and rural areas was estimated to be $21.9 \% .{ }^{24} \mathrm{~A}$ recent cross-sectional survey of a representative sample of 19,003 suburban adults aged 18-76 years in Beijing reported that the prevalence of prehypertension was $35.7 \%$ (38.2\% in men and $31.8 \%$ in women). ${ }^{25}$ Similar to the present findings, several national surveys have also suggested a high prevalence of prehypertension in developing countries. Janghorbani et $\mathrm{al}^{26}$ reported an even higher prevalence of prehypertension in Iranian adults (59.6\% in men and $44.5 \%$ in women) than in the present study. Another survey conducted in rural adults aged $\geq 35$ years old in northeast China showed a prevalence of prehypertension of $47.0 \%$ (51.2\% in men and $42.6 \%$ in women). ${ }^{27}$ Economic development, changes in lifestyle and diet, and an increase in life expectancy may explain the rapid increase in the prevalence and total number of prehypertension cases reported in developing countries. Compared with the results of InterASIA ${ }^{24}$ and the results from Beijing, ${ }^{25}$ the findings in the present study indicate that prehypertension has become a major public health problem in both urban and rural areas of northeast China, and emphasize the urgent need to develop strategies for preventing and treating prehypertension in these regions.

Multivariable logistic regression analysis revealed that age, sex, education level, occupation, family income, smoking, drinking, BMI, WC and lifestyle were significantly associated with the prehypertension status of urban Chinese adults. Higher education status was shown to be a protective factor. Compared with people with no schooling, people with some schooling may have had more opportunities to gain information about hypertension and develop healthy lifestyle habits, so their prevalence was low. Like previous findings ${ }^{9,14,18-27}$ being overweight or obese is associated with prehypertension. Our study found that anthropometric indices of obesity (ie, BMI and WC) remain strong independent determinants of prehypertension status, even after controlling for age, sex and other lifestyle factors. Compared with people of normal weight, those who were obese had a nearly 4-fold higher risk of prehypertension. This result pinpoints the importance of obesity in the progression of hypertension. Evidence suggests that the prevalence of obesity and overweight has reached epidemic proportions worldwide. ${ }^{28}$ In China, according to the China Nationwide Nutrition and Health Survey data, the prevalence of overweight and obesity in adults over 18 years of age has increased by $40 \%$ and $97 \%$, respectively, from $14.6 \%$ in 1992 to $22.8 \%$ in 2002 for overweight, from $3.6 \%$ in 1992 to $7.1 \%$ in 2002 for obesity. ${ }^{29}$ In our study, 33\% of prehypertensive subjects were overweight or obese. Because weight reduction has been shown to lower the odds of hypertension by $77 \%$ over the long term, ${ }^{30}$ weight loss is considered highly important for the present subjects with prehypertension.

Working in organization cadres appears to be associated with a higher risk of developing prehypertension than bluecollar work in urban adult Chinese (adjusted $\mathrm{OR}=1.58,95 \% \mathrm{CI}$ : 1.36-1.82), which may suggest an association between prehypertension and risk factors differences between organization cadres and blue-collar workers. For example, persons who work in organization cadres spend more time sitting in front of their computers and, accordingly, may not get enough exercise and/or may suffer from mental health problems caused by work-related stress. In addition, in the present study, $57.9 \%$ of organization cadre personnel were men, and their average age (40.5 \pm 15.4 years) was higher than that of blue-collar workers (37.8 \pm 13.3 years). We found that current smokers were at lower risk for prehypertension, an observation documented in other studies as well. ${ }^{13,14,31}$ The reason for this association is unclear, and we will continue to study it.

After adjustment for the other factors, our results showed that a controlled diet with low calorie and fat was associated with lower prevalence of prehypertension among urban adults $(\mathrm{aOR}=0.87,95 \% \mathrm{CI}: 0.81-0.94)$, indicating that a healthy life- 
style may be a good method of controlling high BP. The JNC7 report recommends lifestyle modifications for all patients with prehypertension, including losing weight, increasing physical activity, and adopting the Dietary Approaches to Stop Hypertension (DASH) eating plan. ${ }^{32-34}$ Patients who reported adopting these lifestyle modifications were found to be 6-fold more likely to have their hypertension under control. ${ }^{35}$ However, the current study showed that urban Chinese are still facing the serious challenge of a high prevalence of prehypertension and multiple associated risk factors, about which both the general public and health professionals need to be better informed. Prehypertensive people need to understand the seriousness of hypertension and the importance of appropriate lifestyle modification, and healthcare professionals need to know about the guidelines for preventing hypertension and CVD.

\section{Study Limitations}

Two main limitations of the present study should be noted. First, because this was a cross-sectional study, the findings cannot be used to establish a conclusive cause-and-effect relationship between the risk factors and prevalence of prehypertension. Also, Bovet et al. have reported that BP tends to decrease lgreatly across repeated visits on separate days, and the prevalence of high BP based on repeated readings at a second visit will estimate fairly well the true prevalence in the population. ${ }^{36}$ However, in the present study, "hypertension" based on only 1 visit (even if based on the mean of 3 readings), which may markedly overestimate the true prevalence of hypertension.

\section{Conclusions}

Our results indicate that prehypertension is very common in the general urban Chinese adult population and is related to being overweight, central obesity, and many other risk factors, which points to the health benefits of multifaceted lifestyle modification, including weight control and regular physical activity. More effort in implementing nationwide programs of prevention and control of hypertension and overweight, especially in urban northeast China, is needed to reduce the societal burden of hypertension in China.

\section{Acknowledgments}

We express our gratitude to the participants from northeast China. We also thank the anonymous reviewers for their very helpful comments. This research was supported by grants from the Liaoning Province Education Department Foundation (L2010672).

\section{Disclosures}

Declaration of Interest: The authors report no conflicts of interest and they alone are responsible for the content and writing of the paper.

\section{References}

1. He J, Gu D, Wu X, Reynolds K, Duan X, Yao C, et al. Major causes of death among men and women in China. N Engl J Med 2005; 353: $1124-1134$.

2. Lawes CM, Vander HS, Rodgers A. Global burden of blood-pressure-related disease, 2001. Lancet 2008; 371: 1513-1518.

3. Lee DS, Massaro JM, Wang TJ, Kannel WB, Benjamin EJ, Kenchaiah $\mathrm{S}$, et al. Antecedent blood pressure, body mass index, and the risk of incident heart failure in later life. Hypertension 2007; 50: 869-876.

4. Park SJ, Park JB, Choi DJ, Youn HJ, Park CG, Ahn YK, et al; Korean Hypertension Research Network. Detection of masked hypertension and the 'mask effect' in patients with well-controlled office blood pressure. Circ J 2011; 75: 357-365.

5. Okamoto H, Takenaka T, Saitoh Y. Is hypertensive disorder a unique risk factor for peripartum cardiomyopathy and pregnancy-associated cardiomyopathy? Circ J 2011; 75: 1827-1828.

6. Lewington S, Clarke R, Qizilbash N, Peto R, Collins R. Age-specific relevance of usual blood pressure to vascular mortality: A metaanalysis of individual data for one million adults in 61 prospective studies. Lancet 2002; 360: $1903-1913$.

7. Chobanian AV, Bakris GL, Black HR, Cushman WC, Green LA, Izzo JL Jr, et al; National Heart, Lung, and Blood Institute Joint National Committee on Prevention, Detection, Evaluation, and Treatment of High Blood Pressure; National High Blood Pressure Education Program Coordinating Committee. The seventh report of the Joint National Committee on prevention, detection, evaluation, and treatment of high blood pressure: The JNC 7 report. JAMA 2003; 289: 2560-2572.

8. Vasan RS, Larson MG, Leip EP, Evans JC, O’Donnell CJ, Kannel $\mathrm{WB}$, et al. Impact of high-normal blood pressure on the risk of cardiovascular disease. $N$ Engl J Med 2001; 345: $1291-1297$.

9. Ferguson TS, Younger NO, Tulloch-Reid MK, Wright MB, Ward EM, Ashley DE, et al. Prevalence of prehypertension and its relationship to risk factors for cardiovascular disease in Jamaica: Analysis from a cross-sectional survey. BMC Cardiovasc Disord 2008; 8: 20.

10. Hsia J, Margolis KL, Eaton CB, Wenger NK, Allison M, Wu L, et al; Women's Health Initiative Investigators. Women's Health Initiative Investigators. Prehypertension and cardiovascular disease risk in the Women's Health Initiative. Circulation 2007; 115: 855-860.

11. Kim SJ, Lee J, Nam CM, Jee SH, Park IS, Lee KJ, et al. Progression rate from new-onset pre-hypertension to hypertension in Korean adults. Circ J 2011; 75: 135-140.

12. Kokubo Y, Kamide K. High-normal blood pressure and the risk of cardiovascular disease. Circ J 2009; 73: 1381-1385.

13. Okosun IS, Boltri JM, Anochie LK, Chandra KM. Racial/ethnic differences in prehypertension in American adults: Population and relative attributable risks of abdominal obesity. J Hum Hypertens 2004; 18: $849-855$.

14. Agyemang C, van Valkengoed I, van den Born BJ, Stronks K. Prevalence and determinants of prehypertension among African Surinamese, Hindustani Surinamese, and White Dutch in Amsterdam, the Netherlands: The SUNSET study. Eur J Cardiovasc Prev Rehabil 2007; 14: 775-781.

15. Tian S, Dong GH, Wang D, Liu MM, Lin Q, Meng XJ, et al. Factors associated with prevalence, awareness, treatment and control of hypertension in urban adults from 33 communities of China: The CHPSNE Study. Hypertens Res 2011; 34: 1087-1092.

16. Crundy SM, Brewer HB Jr, Cleeman JI, Smith SC Jr, Lenfant C; American Heart Association; National Heart, Lung and Blood Institute. Definition of metabolic syndrome: Report of the National Heart, Lung, and Blood Institute/American heard Association conference on scientific issues related to definition. Circulation 2004; 109: 433 438.

17. International Obesity Task Force. Asia-Pacific perspective: Redefining obesity and its treatment. Western Pacific Region: Sydney, Australia, 2000.

18. Erem C, Hacihasanoglu A, Kocak M, Deger O, Topbas M. Prevalence of prehypertension and hypertension and associated risk factors among Turkish adults: Trabzon Hypertension Study. J Public Health (Oxf) 2009; 31: 47-58.

19. Singh RB, Fedacko J, Pella D, Macejova Z, Ghosh S, de Amit K, et al; Five City Study Group, Gupta AK. Prevalence and risk factors for prehypertension and hypertension in five Indian cities. Acta Cardiol 2011; 66: 29-37.

20. Choi KM, Park HS, Han JH, Lee JS, Lee J, Ryu OH, et al. Prevalence of prehypertension and hypertension in a Korean population: Korean National Health and Nutrition Survey 2001. J Hypertens 2006; 24: $1515-1521$.

21. Ishikawa Y, Ishikawa J, Ishikawa S, Kayaba K, Nakamura Y, Shimada $\mathrm{K}$, et al. Prevalence and determinants of prehypertension in a Japanese general population: The Jichi Medical School Cohort Study. Hypertens Res 2008; 31: 1323-1330.

22. Liu LK, Peng LN, Chen LK, Hwang SJ, Chiou ST. Prehypertension among middle-aged and elderly people in Taiwan: A five-year follow-up. J Atheroscler Thromb 2010; 17: 189-194.

23. Wang Y, Wang QJ. The prevalence of prehypertension and hypertension among US adults according to the new joint national committee guidelines: New challenges of the old problem. Arch Intern Med 2004; 164: 2126-2134.

24. Yu D, Huang J, Hu D, Chen J, Cao J, Li J, et al. Prevalence and risk factors of prehypertension among Chinese adults. J Cardiovasc Pharmacol 2008; 52: 363-368.

25. Zhang WH, Zhang L, An WF, Ma JL. Prehypertension and clustering of cardiovascular risk factors among adults in suburban Beijing, 
China. J Epidemiol 2011; 21: 440-446.

26. Janghorbani M, Amini M, Gouya MM, Delavari A, Alikhani S, Mahdavi A. Nationwide survey of prevalence and risk factors of prehypertension and hypertension in Iranian adults. $J$ Hypertens 2008; 26: 419-426.

27. Sun Z, Zheng L, Wei Y, Li J, Zhang X, Zhang X, et al. Prevalence and risk factors of the rural adult people prehypertension status in Liaoning Province of China. Circ J 2007; 71: 550-553.

28. Nguyen DM, El-Serag HB. The epidemiology of obesity. Gastroenterol Clin North Am 2010; 39: 1-7.

29. Wang Y, Mi J, Shan XY, Wang QJ, Ge KY. Is China facing an obesity epidemic and the consequences? The trends in obesity and chronic disease in China. Int J Obesity 2007; 31: 177-188.

30. He J, Whelton PK, Appel LJ, Charleston J, Klag MJ. Long-term effects of weight loss and dietary sodium reduction on incidence of hypertension. Hypertension 2000; 35: 544-549.

31. Lin SJ, Lee KT, Lin KC, Cheng KH, Tsai WC, Sheu SH, et al. Prevalence of prehypertension and associated risk factors in a rural Taiwanese adult population. Int J Cardiol 2010; 144: 269-273.

32. Svetkey LP, Simons-Morton DG, Proschan MA, Sacks FM, Conlin
PR, Harsha D; DASH-Sodium Collaborative Research Group. Effect of the dietary approaches to stop hypertension (DASH) diet and reduced sodium intake on blood pressure control. J Clin Hypertens 2004; 6: 373-381.

33. Fujise Y, Hanawa K, Takada T, Kikuchi K, Moriguchi O. Studies on etiology of essential hypertension: Hemodynamics, water-sodium balance and response to pressor substances during long-term sodium restriction and after spontaneous blood pressure fall. Jpn Circ J 1975; 39: $597-600$.

34. Fukiyama K, Takishita S, Eto T, Kimura Y, Tomita Y, Kawazoe N. Blood pressure and sympathetic nervous function in spontaneously hypertensive rats derived from breeders on low sodium diet. Jpn Circ J 1986; 50: 1170-1173.

35. He J, Muntner P, Chen J, Roccella EJ, Streiffer RH, Whelton PK. Factors associated with hypertension control in the general population of the United States. Arch Intern Med 2002; 162: 1051-1058.

36. Bovet P, Gervasoni JP, Ross AG, Mkamba M, Mtasiwa DM, Lengeler $\mathrm{C}$, et al. Assessing the prevalence of hypertension in populations: Are we doing it right? J Hypertens 2003; 21: 509-517. 